\title{
Effect of distribution of stickers along backbone on temperature-dependent structural properties in associative polymer solutions
}

\author{
X.-G. Hant*, X.-F. Zhang, Y.-H. Ma \\ School of Mathematics, Physics and Biology, Inmongolia Science and Technology University, \\ Baotou 014010, China \\ Received March 29, 2012, in final form June 8, 2012
}

Effect of distribution of stickers along the backbone on structural properties in associating polymer solutions is studied using self-consistent field lattice model. Only two inhomogeneous morphologies, i.e., microfluctuation homogenous (MFH) and micelle morphologies, are observed. If the system is cooled, the solvent content within the aggregates decreases. When the spacing of stickers along the backbone is increased the temperaturedependent range of aggregation in MFH morphology and half-width of specific heat peak for homogenous solutions-MFH transition increase, and the symmetry of the peak decreases. However, with increasing spacing of stickers, the above three corresponding quantities related to micelles behave differently. It is demonstrated that the broad nature of the observed transitions can be ascribed to the structural changes which accompany the replacement of solvents in aggregates by polymer, which is consistent with the experimental conclusion. It is found that different effect of spacing of stickers on the two transitions can be interpreted in terms of intrachain and interchain associations.

Key words: structural properties, self-consistent field, associative polymer

PACS: $61.25 . \mathrm{Hp}, 64.75 .+\mathrm{g}, 82.60 . \mathrm{Fa}$

\section{Introduction}

Physically associating polymers are polymer chains containing a small fraction of attractive groups along the backbones. The attractive groups tend to form physical links which can play a important role in reversible junctions between different polymer chains. The junctions can be broken and recombined frequently on experimental time scales. This property of the junctions makes associative polymer solutions behave reversibly when ambient conditions, such as temperature and concentrations, change. This tunable characteristic of the system produces extensive applications [1-4] that have a great potential as smart materials [5-7].

Physically associating polymer is simply considered as an amphiphilic block copolymer. When dissolved in a solvent such as water, amphiphilic copolymers can self-assemble into micelles. The solvophobic blocks (attractive groups) cluster together to form a core, and the solvophilic blocks spread outward as a corona. One key effect of solvent selectivity (or equivalently, temperature) is that the micelles dissolve into single chains at a critical micelle temperature as the solvent selectivity decreases. Several studies have investigated the detailed structure of micelles with varying temperature in aqueous solutions [8-11] One appealing advantage of polymers is their versatility. Architectural parameters of associative polymers may be tuned by changing the chain length, chemical composition and distribution of attractive groups [12-18]. It was suggested that the distribution of stickers along the chains can be an important factor in controlling macroscopic properties of these systems [17, 18]. The study of the effect of distribution of sticker along the chain in physically association polymer solutions (PAPSs) would be useful to establish and understand the thermodynamics of block copolymers in a selective solvent.

\footnotetext{
*E-mail: xghan0@163.com
} 
It is well-known that self-consistent field theory (SCFT), as a mean-field theory, has been applied to the study of a great deal of problems in polymeric systems [19-23]. Recently, SCFT is applied to the study of the properties of micelles in polymer solutions [24-26]. In previous paper [27], we focused on the thermodynamic properties and structure transitions in PAPSs. The microfluctuation homogenous (MFH) and micelle morphologies were observed. The degrees of aggregation of micelle morphology is much larger than that of MFH morphology. In this work, the effect of the distribution of stickers along the backbone on structures in PAPSs is studied using a self-consistent field lattice model. The temperatures at which the above two inhomogenous morphologies first appear, denoted by $T_{\mathrm{MFH}}$ and $T_{\mathrm{m}}$, respectively, are dependent on the spacing of sticker along the chain. If the system is cooled from $T_{\mathrm{MFH}}$ and $T_{\mathrm{m}}$, the solvent content within the aggregates (microfluctuation or micellar core) decreases, which is dependent on spacing of sticker and morphology. The increase in spacing of sticker has different effect on homogenous solutions-MFH and MFH-micelle transitions. It is found that this result can be interpreted in terms of intrachain and interchain associations.

\section{Theory}

We consider a system of incompressible PAPSs, where $n_{\mathrm{P}}$ polymers are each composed of $N_{\mathrm{st}}$ segments of type sticker monomer (attractive group) and $N_{\mathrm{ns}}$ segments of type nonsticky monomer, distributed over a lattice. The sticker monomers are placed at the two ends of a chain and regularly along the chain backbone, and there are $l$ nonsticky monomers between two neighboring sticker monomers. The degree of polymerization of chain is $N=N_{\mathrm{st}}+N_{\mathrm{ns}}$. In addition to polymer monomers, $n_{\mathrm{h}}$ solvent molecules are placed on the vacant lattice sites. Stickers, nonsticky monomers and solvent molecules have the same size and each occupies one lattice site. The total number of lattice sites is $N_{L}=n_{\mathrm{h}}+n_{\mathrm{P}} N$. Nearest neighbor pairs of stickers have attractive interaction $-\epsilon$ with $\epsilon>0$, which is the only non-bonded interaction in the present system. In this simulation, however, instead of directly using the exact expression of the nearest neighbor interaction for stickers, we introduce a local concentration approximation for the non-bonded interaction similar to the references [23, 27]. The interaction energy is expressed as:

$$
\frac{U}{k_{\mathrm{B}} T}=-\chi \sum_{r} \widehat{\phi}_{\mathrm{st}}(r) \widehat{\phi}_{\mathrm{st}}(r)
$$

where $\chi$ is the Flory-Huggins interaction parameter in the solutions, which equals $\frac{z}{2 k_{\mathrm{B}} T} \epsilon, z$ is the coordination number of the lattice used, where $\sum_{r}$ means the summation over all the lattice sites $r$ and $\widehat{\phi}_{\text {st }}(r)=\sum_{j} \sum_{s \in \text { st }} \delta_{r, r_{j, s}}$ is the volume fraction of stickers on site $r$, where $j$ and $s$ are the indexes of chain and monomer of a polymer, respectively. $s \in$ st means that the $s$ th monomer belongs to sticker monomer type. We perform the SCFT calculations in the canonical ensemble, and the field-theoretic free energy $F$ is defined as

$$
\frac{F\left[\omega_{+}, \omega_{-}\right]}{k_{\mathrm{B}} T}=\sum_{r}\left[\frac{1}{4 \chi} \omega_{-}^{2}(r)-\omega_{+}(r)\right]-n_{\mathrm{P}} \ln Q_{\mathrm{P}}\left[\omega_{\mathrm{st}}, \omega_{\mathrm{ns}}\right]-n_{\mathrm{h}} \ln Q_{\mathrm{h}}\left[\omega_{\mathrm{h}}\right]
$$

where $Q_{\mathrm{h}}$ is the partition function of a solvent molecule subject to the field $\omega_{\mathrm{h}}(r)=\omega_{+}(r)$, which is defined as $Q_{\mathrm{h}}=\frac{1}{n_{\mathrm{h}}} \sum_{r} \exp \left[-\omega_{\mathrm{h}}(r)\right]$. $Q_{\mathrm{P}}$ is the partition function of a noninteracting polymer chain subject to the fields $\omega_{\mathrm{st}}(r)=\omega_{+}(r)-\omega_{-}(r)$ and $\omega_{\mathrm{ns}}(r)=\omega_{+}(r)$, which act on sticker and nonsticky segments, respectively.

Equation (2.2) can be considered an alternative form of the self-consistent field free energy functional for an incompressible polymer solutions [28]. When a local concentration approximation for the nonbonded interaction is introduced, the SCFT descriptions of lattice model for PAPSs presented in this work is basically equivalent to that of the "Gaussian thread model" chain for the similar polymer solutions [28]. The related illumination in detail refers to reference [27].

Minimizing the free energy function $F$ with $\omega_{-}(r)$ and $\omega_{+}(r)$ leads to the following saddle point equations:

$$
\begin{gathered}
\omega_{-}(r)=2 \chi \phi_{\mathrm{st}}(r), \\
\phi_{\mathrm{st}}(r)+\phi_{\mathrm{ns}}(r)+\phi_{h}(r)=1,
\end{gathered}
$$


where

$$
\phi_{\mathrm{st}}(r)=\frac{1}{N_{L}} \frac{1}{z} \frac{n_{\mathrm{P}}}{Q_{\mathrm{P}}} \sum_{s \in \mathrm{st}} \sum_{\alpha_{s}} \frac{G^{\alpha_{s}}(r, s \mid 1) G^{\alpha_{s}}(r, s \mid N)}{G(r, s)}
$$

and

$$
\phi_{\mathrm{ns}}(r)=\frac{1}{N_{L}} \frac{1}{z} \frac{n_{\mathrm{P}}}{Q_{\mathrm{P}}} \sum_{s \in \mathrm{ns}} \sum_{\alpha_{s}} \frac{G^{\alpha_{s}}(r, s \mid 1) G^{\alpha_{s}}(r, s \mid N)}{G(r, s)}
$$

are the average numbers of sticker and nonsticky segments at $r$, respectively, and

$$
\phi_{\mathrm{h}}(r)=\frac{1}{N_{L}} \frac{n_{\mathrm{h}}}{Q_{\mathrm{h}}} \exp \left\{-\omega_{\mathrm{h}}(r)\right\}
$$

is the average numbers of solvent molecules at $r$. $Q_{\mathrm{P}}$ is expressed as

$$
Q_{\mathrm{P}}=\frac{1}{N_{L}} \frac{1}{z} \sum_{r_{N}} \sum_{\alpha_{N}} G^{\alpha_{N}}(r, N \mid 1),
$$

where $r_{N}$ and $\alpha_{N}$ denote the position and orientation of the $N$ th segment of the chain, respectively. $\sum_{r_{N}} \sum_{\alpha_{N}}$ means the summation over all the possible positions and orientations of the $N$ th segment of the chain. $G^{\alpha_{s}}(r, s \mid 1)$ and $G^{\alpha_{s}}(r, s \mid N)$ are the end segment distribution functions of the sth segment of the chain. $G(r, s)$ is the free segment weighting factor. The expressions of the above three quantities refer to Appendix. In this work, the chain is described as a random walk without the possibility of direct backfolding. Although self-intersections of a chain are not permitted, the excluded volume effect is sufficiently taken into account [29].

The saddle point is calculated using the pseudo-dynamical evolution process [27]. The calculation is initiated from appropriately random-chosen fields $\omega_{+}(r)$ and $\omega_{-}(r)$, and interrupted when the change of free energy $F$ between two successive iterations is reduced to the needed precision. The resulting configuration is taken as a saddle point one. By comparing the free energies of the saddle point configurations obtained from different initial fields, the relative stability of the observed morphologies can be assessed.

\section{Result and discussion}

In our studies, the properties of associative polymer solutions depend on four tunable parameters: $\chi$ is the Flory-Huggins interaction parameter, $N$ is the degree of polymerization of chain, where $N$ equals 81 in this paper, $l$ is the spacing of stickers along the backbone and $\bar{\phi}_{\text {st }}$ is the average volume fraction of polymers. The calculations are performed in a three-dimensional simple cubic lattice with periodic boundary condition, and the effect of the lattice size is considered. The results presented below are obtained from the lattice with $N_{L}=40^{3}$. Three different morphologies in PAPSs are observed, i.e., the homogenous, micro-fluctuation homogenous (MFH) and micelle morphologies. By comparing the relative stability of the observed states, the phase diagram is constructed.

Figure 1 shows the phase diagram of the systems with different spacing of stickers $l$. At fixed $l$, when $\chi$ is increased from homogenous solutions, MFH and micelle morphologies appear in turn. $\phi_{\mathrm{P}}(r)$ and $\phi_{\mathrm{st}}(r)$ in the solutions with MFH morphology slightly fluctuate around $\bar{\phi}_{\mathrm{P}}$ and $\bar{\phi}_{\text {st }}$, respectively. The average volume fraction of stickers at the sticker-rich sites (fluctuations) $r_{\text {ri }}$ increases with increasing $\chi$ for fixed $\bar{\phi}_{\mathrm{P}}$. Its maximum value is about $2 \bar{\phi}_{\text {st }}$, which is much smaller than unity for all the $\bar{\phi}_{\mathrm{P}}$. There exists the state of microfluctuations whose thermodynamics is adequately captured by SCFT. It is confirmed that the MFH appearance is accompanied by the appearance of the heat capacity peak (shown below), which is in reasonable agreement with the conclusion drawn by Kumar et al. [27, 30]. The basic component of micelle morphology is flower micelles, which are randomly and closely distributed in the system. Each micelle has a sticker-rich core, which is located at the center of a micelle, surrounded by non-sticky components of polymers. The average value of volume fraction of stickers at the micellar core is much larger than that of sticker-rich sites in MFH morphology. It is shown that the degree of aggregation of stickers in micelle morphology is much larger than that in MFH morphology.

When spacing of stickers $l$ is changed, only MFH morphology and micelles are observed as inhomogeneous morphologies. The structural morphology of MFH morphology does not change, and the micellar 


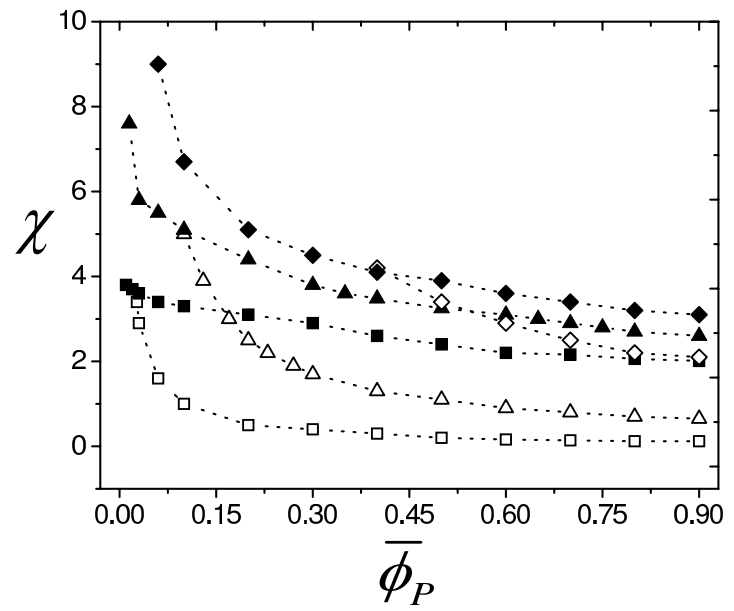

Figure 1. The phase diagram for systems with different spacing of stickers $l$. The boundaries of MFH and micelle morphologies are obtained. The red open and solid squares, green open and solid triangles, blue open and solid diamonds correspond to the boundaries of MFH and micelle morphologies for $l=3,9,19$, respectively.

shape remains spherelike. For $l=19$, the $\chi$ value on micellar boundary $\left(\sim 1 / T_{\mathrm{m}}\right)$ increases with decreasing $\bar{\phi}_{\mathrm{P}}$. When $\bar{\phi}_{\mathrm{P}}$ goes down to a certain extent, micellar boundary becomes steep. The $\chi$ value on MFH boundary $\left(\sim 1 / T_{\mathrm{MFH}}\right)$ also rises with a decrease in $\bar{\phi}_{\mathrm{P}}$. MFH boundary intersects the micellar one at $\bar{\phi}_{\mathrm{CFC}}$, which is the critical MFH concentration $\left(\bar{\phi}_{\mathrm{CFC}}=0.4\right)$. When $l$ is decreased, at fixed $\bar{\phi}_{\mathrm{P}}$, the $\chi$ value on micellar boundary shifts to a small value, and the $\chi$ value on MFH boundary decreases markedly. $\bar{\phi}_{\text {CFC }}$ also drops with a decrease in $l$.

In this paper, the structural properties dependent on temperature are focused. Therefore, the quantities related to volume fractions of stickers in MFH and micelle morphologies as a function of $\chi$ are studied. Figure2 2(a) shows the variations of effective average volume fractions of stickers and solvents at

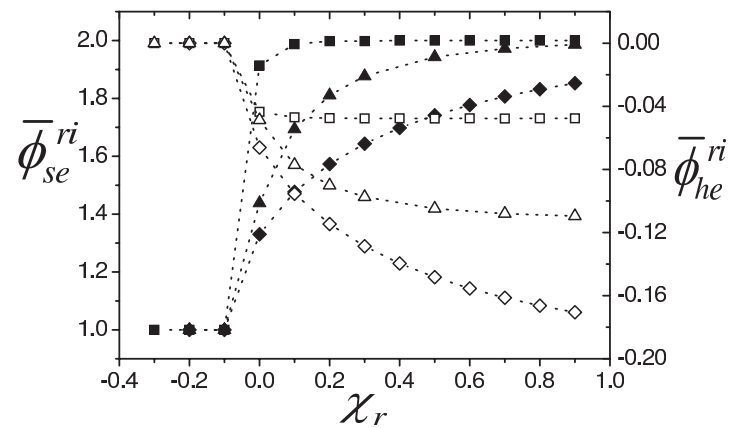

(a)

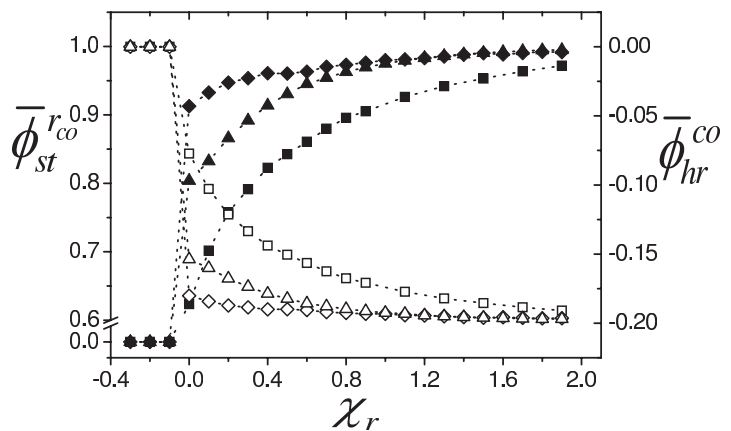

(b)

Figure 2. The variations of effective average volume fractions of stickers and solvents at the stickerrich sites in MFH morphologies with different spacing of stickers $l$, denoted by $\bar{\phi}_{\mathrm{se}}^{\mathrm{ri}}\left[=\bar{\phi}_{\mathrm{st}}^{\mathrm{ri}} / \bar{\phi}_{\mathrm{st}}\right]$ and $\bar{\phi}_{\text {he }}^{\text {ri }}\left[=\left(\bar{\phi}_{\mathrm{h}}^{\mathrm{ri}}-\bar{\phi}_{\mathrm{h}}\right) / \bar{\phi}_{\mathrm{st}}\right]$, respectively, with the $\chi$ deviation from MFH boundary $\chi_{\mathrm{r}}$ at $\bar{\phi}_{\mathrm{P}}=0.8$ are presented in figure 2(a); The variations of the average volume fraction of stickers and relative average volume fraction of solvents at the micellar cores, denoted by $\bar{\phi}_{\mathrm{st}}^{r_{\mathrm{co}}}$ and $\bar{\phi}_{\mathrm{hr}}^{r_{\mathrm{co}}}\left[=\bar{\phi}_{\mathrm{h}}^{r_{\mathrm{co}}}-\bar{\phi}_{\mathrm{h}}\right]$, respectively, with the $\chi$ deviation from micellar boundary $\chi_{\mathrm{r}}$ in the systems with different spacing of stickers $l$ at $\bar{\phi}_{\mathrm{P}}=0.8$ are shown in figure $2(\mathrm{~b})$.

the sticker-rich sites (microfluctuations) in MFH morphologies with different spacing of stickers $l$, which are denoted by $\bar{\phi}_{\mathrm{se}}^{\mathrm{ri}}$ and $\bar{\phi}_{\mathrm{he}}^{\mathrm{ri}}$, respectively, with the $\chi$ deviation from MFH boundary, $\chi_{\mathrm{r}}$, at $\bar{\phi}_{\mathrm{P}}=0.8$, where $\bar{\phi}_{\mathrm{se}}^{\mathrm{ri}}$ and $\bar{\phi}_{\mathrm{he}}^{\mathrm{ri}}$ equal $\bar{\phi}_{\mathrm{st}}^{\mathrm{ri}} / \bar{\phi}_{\mathrm{st}}$ and $\left(\bar{\phi}_{\mathrm{h}}^{\mathrm{ri}}-\bar{\phi}_{\mathrm{h}}\right) / \bar{\phi}_{\mathrm{st}}$, respectively. With the increase in $\chi_{\mathrm{r}}, \bar{\phi}_{\mathrm{se}}^{\mathrm{ri}}$ at $l=3$ initially 
rises when $0 \leqslant \chi_{\mathrm{r}} \leqslant 0.2$ and then maintains a certain value, and the corresponding $\bar{\phi}_{\text {he }}^{\mathrm{ri}}$ first decreases when $0 \leqslant \chi_{\mathrm{r}} \leqslant 0.2$ and then remains constant. Although the increase of the degree of aggregation in MFH morphology is accompanied by the penetration of solvents, the effective total quantity of penetration of solvents is very small $\left(\left|\bar{\phi}_{\text {he }}^{\mathrm{ri}}\right|=0.047\right)$. When $l$ is increased, the shapes of the curves of $\bar{\phi}_{\text {se }}^{\mathrm{ri}}\left(\chi_{\mathrm{r}}\right)$ and $\bar{\phi}_{\text {he }}^{\mathrm{ri}}\left(\chi_{\mathrm{r}}\right)$ are similar to the case of $l=3$. However, the onset of the range independent of $\chi_{\mathrm{r}}$ shifts to a larger $\chi_{\mathrm{r}}$ value. The minimum of $\bar{\phi}_{\mathrm{he}}^{\mathrm{ri}}\left(\chi_{\mathrm{r}}\right)$ goes down with an increasing $l$. It is demonstrated that in MFH morphology the increase in spacing of stickers augments the temperature-dependent range of aggregation of stickers and accelerates the effective penetration of solvents.

The variations of the average volume fraction of stickers and the relative average volume fraction of solvents at the micellar cores, which are denoted by $\bar{\phi}_{\mathrm{st}}^{r_{\mathrm{co}}}$ and $\bar{\phi}_{\mathrm{hr}}^{r_{\mathrm{co}}}\left(=\bar{\phi}_{\mathrm{h}}^{r_{\mathrm{co}}}-\bar{\phi}_{\mathrm{h}}\right)$, respectively, with the $\chi$ deviation from micellar boundary, $\chi_{\mathrm{r}}$, in the systems with different spacings of stickers $l$ at $\bar{\phi}_{\mathrm{P}}=0.8$ are shown in figure 2 (b). At $l=3, \bar{\phi}_{\mathrm{st}}^{r_{\mathrm{co}}}$ rises and approaches 1 , and the corresponding $\bar{\phi}_{\mathrm{hr}}^{r_{\mathrm{co}}}$ decreases and is close to its minimum when $\chi_{\mathrm{r}}$ is increased. When $l$ is increased, $\bar{\phi}_{\mathrm{st}}^{r_{\mathrm{co}}}$ goes up and rapidly approaches 1 , and the corresponding $\bar{\phi}_{\mathrm{hr}}^{r_{\mathrm{co}}}$ goes down and is quickly close to its minimum, with increasing $\chi_{\mathrm{r}}$. It is demonstrated that in micelle morphology, the increase in spacing of stickers almost does not change the total quantity of the expelled solvent, and decreases the effective range of aggregation dependent on $\chi_{\mathrm{r}}$, which is contrary to that of MFH morphology.

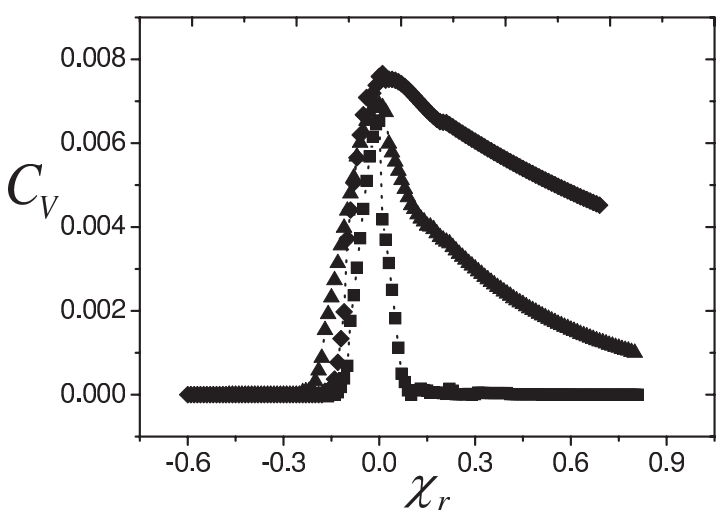

(a)

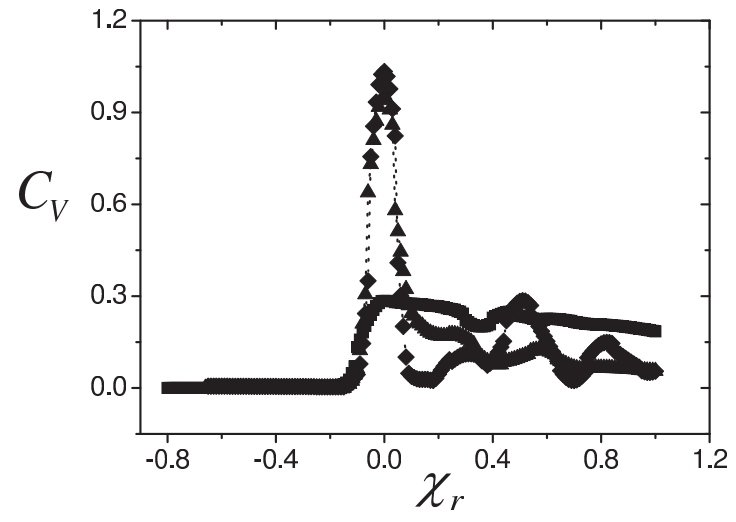

(b)

Figure 3. (Color online) The variations of the specific heat $C_{\mathrm{V}}$ with the $\chi$ deviation from MFH or micellar boundary $\chi_{\mathrm{r}}$ in HS-MFH and MFH-micelle transition regions at $\bar{\phi}_{\mathrm{P}}=0.8$ in the systems with different spacing of stickers $l$ are presented in figures 3 (a) and (b), respectively. The red squares, green triangles and blue diamonds correspond to $l=3,9,19$, respectively.

In order to demonstrate the property of the observed transition, the heat capacity $C_{\mathrm{V}}$ is calculated, because the half-width of a specific heat peak may be an intrinsic measure of transition broadness [31]. In this work, the heat capacity per site of PAPSs is expressed as follows (in the unit of $k_{\mathrm{B}}$ ):

$$
\begin{aligned}
C_{\mathrm{V}} & =\left(\frac{\partial U}{\partial T}\right)_{N_{L}, n_{\mathrm{P}}} \\
& =\frac{1}{N_{L}} \chi^{2} \frac{\partial}{\partial \chi}\left(\sum_{r} \phi_{\mathrm{st}}^{2}(r)\right) .
\end{aligned}
$$

The $C_{\mathrm{V}}\left(\chi_{\mathrm{r}}\right)$ curves for the HS-MFH and MFH-micelle transitions in various $l$ at $\bar{\phi}_{\mathrm{P}}=0.8$ are shown in figures 3 (a) and 3(b), respectively. For HS-MFH transition, a peak appears in each $C_{\mathrm{V}}\left(\chi_{\mathrm{r}}\right)$ curve. When $l$ is increased, the height and half-width of the transition peak rise, and the symmetry of the peak decreases. Meanwhile, for the MFH-micelle transition, there are some peaks in each $C_{\mathrm{V}}\left(\chi_{\mathrm{r}}\right)$ curve. The highest of these peaks, corresponds to MFH-micelle transition. When $l$ is increased, the height of the transition peak rises, and the corresponding half-width does go down. The shape of the transition peak tends to be symmetric under the condition of an increasing $l$. It is shown that an increase in $l$ causes an increase in the broadness of HS-MFH transition and a decrease in the broadness of MFH-micelle transition. The effect 
of spacing of stickers on $C_{\mathrm{V}}\left(\chi_{\mathrm{r}}\right)$ curve for the MFH-micelle transition is different from that for HS-MFH transition.

The HS-MFH transition that took place in this work, which corresponds to the clustering transition observed by Kumar et al. [27, 30], is affected by the change of spacing of stickers as discussed above. When spacing of stickers is increased, both the magnitude of the temperature-dependent range of aggregation and the effective total quantity of the expelled solvents in MFH morphology increase. Under the same condition, the broadness of the corresponding transition also increases. Meanwhile, for MFH-micelle transition, an increase of spacing of stickers results in a decrease of the magnitude of the effective range dependent on temperature and on the transition broadness. Overall, for the above two transitions, the magnitude of the temperature-dependent range of aggregation and the transition broadness change simultaneously and consistently with the spacing of stickers. It is demonstrated that the broad nature of the transitions observed in PAPSs is concerned with the penetration of solvents from the aggregates, which is in reasonable agreement with the experimental result observed by Goldmints et al. in the unimer-micelle transition [32]. At the same time, it is found that the symmetry of a specific heat peak is affected by the process of penetration of solvents. When the transition broadness increases, the symmetry of a transition peak decreases. Furthermore, from the above behaviors of penetration of a solvent and heat capacity, it is seen that an increase of spacing of stickers has different effect on the HS-MFH and MFH-micelle transitions.

In order to interpret the different effect of spacing of stickers on the aggregation of stickers in MFH and micelle morphologies, we evaluate the probability that a sticker of polymer chain forms intrachain and interchain associations in the system using an approach similar to the one presented in reference \27, 33, 34]. We suppose that there are no other sticker aggregates in the MFH and micellar system except sticker-rich site microfluctuations or the micellar cores. A sticker in a particular chain can form an intrachain association, as well as an interchain association. Ignoring the probabilities that more than two stickers of a definite chain are attached to an aggregate, the conditional probability that the sticker $s_{1}$ is concerned with intrachain association, provided that the sticker $s_{1}$ is at an aggregate of the two above mentioned types whose position locates at $r_{\mathrm{ag}}$, can be expressed as:

$$
p_{\text {loop }}\left(r_{\mathrm{ag}}, s_{1}\right)=\frac{1}{P^{(1)}\left(r_{\mathrm{ag}}, s_{1}\right)} \sum_{s_{2} \in \mathrm{st}, s_{2} \neq s_{1}} P^{(2)}\left(r_{\mathrm{ag}}, s_{1} ; r_{\mathrm{ag}}, s_{2}\right),
$$

where $\sum_{s_{2} \in \text { st, } s_{2} \neq s_{1}}$ means the summation over all the stickers of a polymer chain except the $s_{1}$ th one, while $P^{(1)}\left(r_{\mathrm{ag}}, s_{1}\right)$ and $P^{(2)}\left(r_{\mathrm{ag}}, s_{1} ; r_{\mathrm{ag}}, s_{2}\right)$, whose expressions are given in appendix, are the single-segment and two-segment probability distribution functions of a chain, respectively. Then, $1-p_{\text {loop }}\left(r_{\mathrm{ag}}, s_{1}\right)$ is the conditional probability that the sticker $s_{1}$ is linked with those that belong to other chains when the sticker $s_{1}$ is at $r_{\mathrm{ag}}$, and

$$
\mathbf{P}_{l k}\left(s_{1}\right)=\sum_{r_{\mathrm{ag}}} P^{(1)}\left(r_{\mathrm{ag}}, s_{1}\right)\left[1-p_{\mathrm{loop}}\left(r_{\mathrm{ag}}, s_{1}\right)\right]
$$

is the probability that a sticker $s_{1}$ of a chain is related to an interchain association, where $\sum_{r_{\mathrm{ag}}}$ means the summation over all the aggregates in the system. The summation of $\mathbf{P}_{l k}\left(s_{1}\right)$ over all the stickers in a chain, $\left\langle n_{l k}\right\rangle=\sum_{s_{1}, s_{1} \in \text { st }} \mathbf{P}_{l k}\left(s_{1}\right)$, can be viewed as the average sticker number from a particular polymer chain linked with other chains by sticker aggregates. The average fraction of interchain association of a sticker is expressed as $\bar{f}_{t e}=\left\langle n_{l k}\right\rangle / N_{\mathrm{st}}$. The average fraction of intrachain association of a sticker is defined as $\bar{f}_{\text {tr }}=\left(1 / N_{\text {st }}\right) \sum_{s_{1}, s_{1} \in \mathrm{st}} \sum_{r_{\mathrm{ag}}} p_{\text {loop }}\left(r_{\mathrm{ag}}, s_{1}\right)$.

Figure 4 shows the variations of average fractions of intrachain association and interchain association of a sticker, denoted by $\bar{f}_{\text {tr }}$ and $\bar{f}_{\text {te }}$, respectively, with the $\chi$ deviation from the MFH or micellar boundary, $\chi_{\mathrm{r}}$, in the system with different spacing of stickers $l$ at $\bar{\phi}_{\mathrm{P}}=0.8$. In MFH morphology [figure 4(a)], when $\chi_{\mathrm{r}}$ is increased, $\bar{f}_{\text {te }}$ at $l=3$ first rises when $0 \leqslant \chi_{\mathrm{r}} \leqslant 0.2$, then maintains a certain value, and the corresponding $\bar{f}_{\text {tr }}$ always remains constant when $\chi_{\mathrm{r}}>0$, and $\bar{f}_{\text {tr }}$ is smaller than $\bar{f}_{\text {te }}$. When $l$ is increased, the variation of $\bar{f}_{\text {te }}$ with $\chi_{\mathrm{r}}$ resembles that of $l=3$. However, a certain value at which $\bar{f}_{\text {te }}$ finally arrives rises, and the corresponding $\chi_{\mathrm{r}}$ also goes up, with $\chi_{\mathrm{r}}$ increasing. $\bar{f}_{\text {tr }}$ decreases markedly when $l$ is increased. $\bar{f}_{\text {tr }}$ is much smaller than the corresponding $\bar{f}_{\text {te }}$. It is shown that in MFH morphology intrachain association is independent of $\chi_{\mathrm{r}}$, and the range of interchain association which is concerned with $\chi_{\mathrm{r}}$ rises when spacing of stickers is increased. In micelle morphology [figure 4(b)], the variation of the average fraction of interchain association of a sticker $\bar{f}_{\text {te }}$ with the deviation from micellar boundary $\chi_{\mathrm{r}}$ and the effect of $l$ 


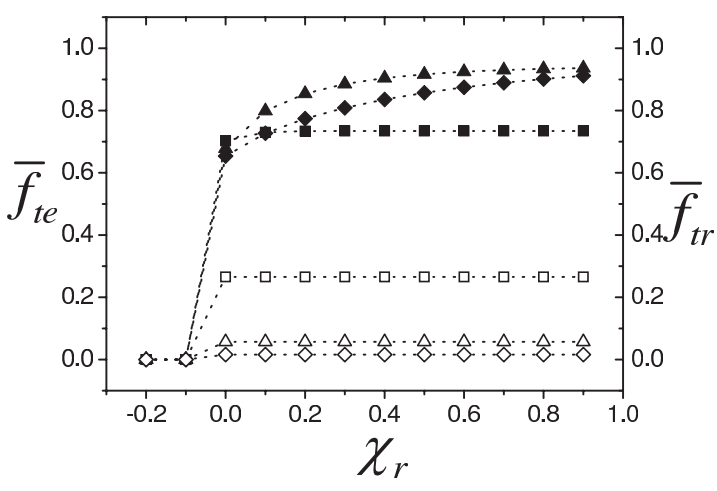

(a)

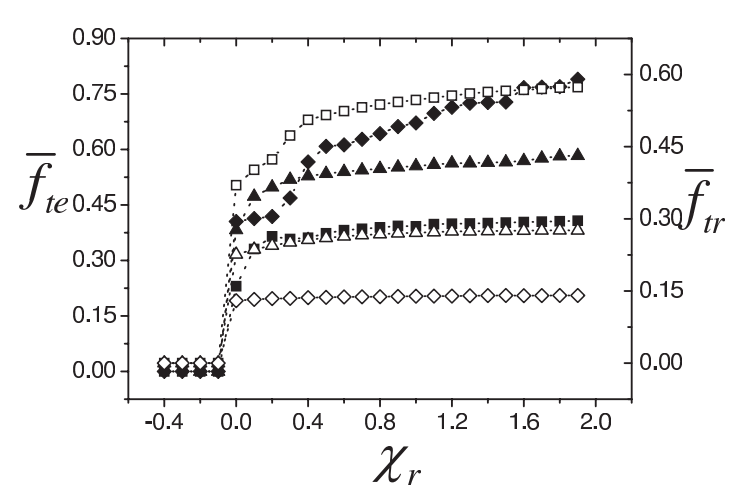

(b)

Figure 4. The average fractions of intrachain and interchain associations of a sticker, denoted by $\bar{f}_{\text {tr }}$ and $\bar{f}_{\text {te }}$, respectively, as functions of the $\chi$ deviation from MFH or micellar boundary $\chi_{\mathrm{r}}$ are presented in figures 4 (a) and (b) in MFH and micelle morphologies in the systems with different spacing of stickers $l$ at $\bar{\phi}_{\mathrm{P}}=0.8$. The red open and solid squares, green open and solid triangles, blue open and solid diamonds correspond to by $\bar{f}_{\text {tr }}$ and $\bar{f}_{\text {te }}$ of $l=3,9,19$, respectively.

on it are similar to those of MFH morphology. However, there exists an evident difference in the curve of $\bar{f}_{\text {te }}\left(\chi_{\mathrm{r}}\right)$, which is not smooth. The intrachain associations of micelles $\bar{f}_{\text {tr }}$ are dependent on $\chi_{\mathrm{r}}$. The behavior is distinct for small $l$ and different from MFH morphology. It is noted that at $l=3$, when $0<\chi_{\mathrm{r}} \leqslant 0.4$, the extent of rise of $\bar{f}_{\text {tr }}$ and $\bar{f}_{\text {te }}$ changes alternately with increasing $\chi_{\mathrm{r}}$.

As discussed above, the increase of spacing of stickers $l$ has different effect on the HS-MFH and MFHmicelle transitions, which can be explained in terms of intrachain and interchain associations. The average fraction of interchain association of a sticker in MFH morphology $\bar{f}_{\mathrm{te}}^{\mathrm{ri}}$ is much larger than that of the corresponding intrachain quantity $\bar{f}_{\mathrm{tr}}^{\mathrm{ri}}$, and $\bar{f}_{\mathrm{tr}}^{\mathrm{ri}}$ is absolutely independent of temperature. Therefore, the temperature-dependent property of MFH morphology is determined by interchain association. When $l$ is increased, $\bar{f}_{\text {te }}^{\text {ri }}$ range concerned with temperature also rises. Therefore, an increase of spacing of stickers is favorable to an increase in the broadness of HS-MFH transition. Meanwhile, in micelle morphology, the average fraction of intrachain association of a sticker $\bar{f}_{\mathrm{tr}}^{\text {ro }}$ is dependent on temperature, especially in the case of small $l$. Therefore, the property of MFH-micelle transition is determined by both intrachain and interchain associations [figure 4(b)]. At $l=3$, both $\bar{f}_{\text {tr }}^{\text {ro }}$ and $\bar{f}_{\text {te }}^{\text {ro }}$ are sensitive to temperature in the transition region. When $l$ is increased, the susceptibility of $\bar{f}_{\text {tr }}^{\text {ro }}$ to temperature decreases markedly. Although an increase in $l$ is favorable to an increase in the susceptibility of $\bar{f}_{\text {te }}^{\text {ro }}$ to temperature, it may be weak compared with the corresponding decrease of $\bar{f}_{\mathrm{tr}}^{\text {ro }}$. Therefore, when spacing of stickers is increased, the broadness of the corresponding MFH-micelle transition decreases, which is different from that of HS-MFH transition.

\section{Conclusion and summary}

The effect of distribution of stickers along the backbone on the temperature-dependent property of aggregation structure in physically associating polymer solutions (PAPSs) is studied using the self-consistent field lattice model. When spacing of stickers is increased, the temperature susceptibility of penetration of solvents from aggregates in MFH morphology and the broadness of HS-MFH transition increases. However, the corresponding two quantities of MFH-micelle transition do decrease under the same condition, which is opposite to that of HS-MFH transition. It is found that the temperature susceptibility of penetration of solvents from the two above morphologies and the broadness of the two transitions change simultaneously and consistently. It is demonstrated that the broadness of the transitions observed in PAPSs is concerned with the penetration of solvent from aggregates. Furthermore, the different effect of spacing of stickers on HS-MFH and MFH-micelle transitions is due to different contributions of intrachain and interchain associations to MFH and micelle morphologies. This work can be extended to the study of the effects of polymer concentration and chain architecture on the transition properties related to the penetration of a solvent. 


\section{Acknowledgements}

This research is financially supported by the National Nature Science Foundations of China (11147132) and the Inner Mongolia municipality (2012MS0112), and the Innovative Foundation of Inner Mongolia University of Science and Technology (2011NCL018).

\section{Appendix}

Following the scheme of Schentiens and Leermakers [35], $G^{\alpha_{s}}(r, s \mid 1)$ is the end segment distribution function of the $s$ th segment of the chain, which is evaluated from the following recursive relation:

$$
G^{\alpha_{s}}(r, s \mid 1)=G(r, s) \sum_{r_{s-1}^{\prime}} \sum_{\alpha_{s-1}} \lambda_{r_{s}-r_{s-1}^{\prime}}^{\alpha_{s}-\alpha_{s-1}} G^{\alpha_{s-1}}\left(r^{\prime}, s-1 \mid 1\right)
$$

where $G(r, s)$ is the free segment weighting factor and is expressed as

$$
G(r, s)= \begin{cases}\exp \left[-\omega_{\mathrm{st}}\left(r_{s}\right)\right], & s \in \mathrm{st} \\ \exp \left[-\omega_{\mathrm{ns}}\left(r_{s}\right)\right], & s \in \mathrm{ns}\end{cases}
$$

The initial condition is $G^{\alpha_{1}}(r, 1 \mid 1)=G(r, 1)$ for all the values of $\alpha_{1}$. In the above expression, the values of $\lambda_{r_{s}-r_{s-1}^{\prime}}^{\alpha_{s}-\alpha_{s-1}}$ depend on the chain model used. We assume that

$$
\lambda_{r_{s}-r_{s-1}^{\prime}}^{\alpha_{s-1}}= \begin{cases}0, & \alpha_{s}=\alpha_{s-1} \\ 1 /(z-1), & \text { otherwise }\end{cases}
$$

This means that the chain is described as a random walk without the possibility of direct backfolding. Another end segment distribution function $G^{\alpha_{s}}(r, s \mid N)$ is evaluated from the following recursive relation:

$$
G^{\alpha_{s}}(r, s \mid N)=G(r, s) \sum_{r_{s+1}^{\prime}} \sum_{\alpha_{s+1}} \lambda_{r_{s+1}^{\prime}-r_{s}}^{\alpha_{s+1}-\alpha_{s}} G^{\alpha_{s+1}}\left(r^{\prime}, s+1 \mid N\right)
$$

with the initial condition $G^{\alpha_{N}}(r, N \mid N)=G(r, N)$ for all the values of $\alpha_{N}$.

Using the expressions of the end segment distribution functions, the single-segment probability distribution function $P^{(1)}(r, s)$ and the two-segment probability distribution function $P^{(2)}\left(r_{1}, s_{1} ; r_{2}, s_{2}\right)$ of the chain can be defined as follows:

$$
P^{(1)}(r, s)=\frac{1}{z N_{L} Q_{\mathrm{P}}} \sum_{r_{s}^{\prime}} \sum_{\alpha_{s}} \frac{G^{\alpha_{s}}\left(r^{\prime}, s \mid 1\right) G^{\alpha_{s}}\left(r^{\prime}, s \mid N\right)}{G\left(r^{\prime}, s\right)} \delta_{r_{s}^{\prime}, r}
$$

which is a normalized probability that the monomer $s$ of the chain is on the lattice site $r$;

$$
\begin{aligned}
P^{(2)}\left(r_{1}, s_{1} ; r_{2}, s_{2}\right)= & \frac{1}{z N_{L} Q_{\mathrm{P}}} \sum_{r_{s_{1}}^{\prime}} \sum_{\alpha_{s_{1}}} \sum_{r_{s_{2}}^{\prime}} \sum_{\alpha_{s_{2}}} G^{\alpha_{s_{1}}}\left(r^{\prime}, s_{1} \mid 1\right) \delta_{r_{s_{1}}^{\prime}, r_{1}} \\
& \times \mathscr{G}\left(r^{\prime}, s_{1} ; r^{\prime}, s_{2}\right) G^{\alpha_{s_{2}}}\left(r^{\prime}, s_{2} \mid N\right) \delta_{r_{s_{2}}^{\prime}, r_{2}}
\end{aligned}
$$

and

$$
\mathscr{G}\left(r, s_{1} ; r, s_{2}\right)=\sum_{r_{s_{1}+1}} \sum_{\alpha_{s_{1}+1}} \ldots \sum_{r_{s_{2}-1}} \sum_{\alpha_{s_{2}-1}}\left\{\prod_{s=s_{1}+1}^{s_{2}-1} \lambda_{r_{s}-r_{s-1}}^{\alpha_{s}-\alpha_{s-1}} G(r, s)\right\} \lambda_{r_{s_{2}}-r_{s_{2}-1}}^{\alpha_{s_{2}-\alpha_{s_{2}-1}}} \quad\left(\text { for } s_{2}>s_{1}\right)
$$

give the probability that the monomers $s_{1}$ and $s_{2}$ of the chain are on the lattice sites $r_{1}$ and $r_{2}$, respectively. It can be verified that $\sum_{r} P^{(1)}(r, s)=1$, and $\sum_{r_{2}} P^{(2)}\left(r_{1}, s_{1} ; r_{2}, s_{2}\right)=P^{(1)}\left(r_{1}, s_{1}\right)$. 


\section{References}

1. Clark A.H., Ross-Murphy S.B., Adv. Polym. Sci., 1987, 83, 57; doi $10.1007 /$ BFb0023332

2. Slater G.W., Kist T.B.L., Ren H., Drouin G., Electrophoresis, 1998, 19, 1525; doi 10.1002/elps.1150191003

3. Tonge S.R., Tighe B.J., Adv. Drug Delivery Rev., 2001, 53, 109; doi 10.1016/S0169-409X(01)00223-X

4. Taylor K.C., Nasr-El-Din H.A., J. Pet. Sci. Eng., 1998, 19, 265; doi 10.1016/S0920-4105(97)00048-X

5. Brunsveld L., Folmer B.J.B., Meijer E.W., Sijbesma R.P., Chem. Rev., 2001, 101, 4071; doi 10.1021/cr990125q

6. De Greef T.F.A., Meijer E.W., Nature, 2008, 453, 171; doi 10.1038/453171a

7. Cordier P., Tournilhac F., Soulie-Ziakovic C., Leibler L., Nature, 2008, 451, 977; doi 10.1038/nature06669.

8. Pedersen J.S., Svaneborg C., Almdal K., Hamley I.W., Young R.N., Macromolecules, 2003, 36, 416; doi $10.1021 / \mathrm{ma} 0204913$

9. Sommer C., Pedersen J.S., Macromolecules, 2004, 37, 1682; doi $10.1021 / \mathrm{ma} 0357669$

10. Castelletto V., Hamley I.W., Pedersen J.S., Langmuir, 2004, 20, 2992; doi 10.1021/la036231b.

11. Bang J., Viswanathan K., Lodge T.P., Park M.J., Char K., J. Chem. Phys., 2004, 121, 11489; doi 10.1063/1.1812753

12. Chassenieux C., Nicolai T., Durand D., Francuois J., Macromolecules, 1998, 31, 4035; doi 10.1021/ma9802273.

13. Beaudoin E., Borisov O., Lapp A., Billon L., Hiorns R.C., Francuois J., Macromolecules, 2002, 35, 7436; doi $10.1021 / \mathrm{ma} 011027 \mathrm{l}$

14. Beaudoin E., Gourier C., Hiorns R.C., Francuois J., J. Colloid Interface Sci., 2002, 251, 398; doi $10.1006 /$ jcis.2002.8402

15. Lafleche F., Durand D., Nicolai T., Macromolecules, 2003, 36, 1331; doi 10.1021/ma021076d

16. Lafleche F., Nicolai T., Durand D., Gnanou Y., Taton D., Macromolecules, 2003, 36, 1341; doi 10.1021/ma0210776

17. Brown G., Chakrabarti A., J. Chem. Phys., 1992, 96, 3251; doi $10.1063 / 1.461969$.

18. Gindy M.E., Prud'homme R.K., Panagiotopoulos A.Z., J. Chem. Phys., 2008, 128, 164906; doi 10.1063/1.2905231

19. Orland H., Schick M., Macromolecules, 1996, 29, 713; doi 10.1021/ma9508461

20. Matsen M.W., Schick M., Phys. Rev. Lett., 1994, 72, 2660; doi 10.1103/PhysRevLett.72.2660

21. Tang P., Qiu F., Zhang H.D., Yang Y.L., Phys. Rev. E, 2004, 69, 031803; doi 10.1103/PhysRevE.69.031803

22. He X., Liang H., Huang L., Pan C., J. Phys. Chem. B, 2004, 108, 1731; doi 10.1021/jp0359337

23. Chen J.Z., Zhang C.X., Sun Z.Y., Zheng Y.S., An L.J., J. Chem. Phys., 2006, 124, 104907; doi 10.1063/1.2176619.

24. Cavallo A., Mu1ller M., Binder K., Macromolecules, 2006, 39, 9539; doi 10.1021/ma061493g

25. Jelinek K., Limpouchova Z., Uhlk F., Prochazka K., Macromolecules, 2007, 40, 7656; doi 10.1021/ma070928c

26. Charlaganov M., Borisov O.V., Leermakers F.A.M., Macromolecules, 2008, 41, 3668; doi 10.1021/ma800130q

27. Han X.G., Zhang C.X., J. Chem. Phys., 2010, 132, 164905; doi 10.1063/1.3400648

28. Fredrickson G.H., The Equilibrium Theory of Inhomogenous Polymers. Clarendon Press, Oxford, 2005.

29. Medvedevskikh Y.G., Condens. Matter Phys., 2001, 4, 209.

30. Kumar S.K., Doughlas J.F., Phys. Rev. Lett., 2001, 87, 188301; doi 10.1103/PhysRevLett.87.188301

31. Douglas J.F., Dudowicz J., Freeda K.F., J. Chem. Phys., 2006, 125, 114907; doi 10.1063/1.2356863

32. Goldmints I., Gottberg F.K.V., Smith K.A., Hatton T.A., Langmuir, 1997, 13, 3659; doi 10.1021/la970140v

33. Matsen M.W., Thompson R.B., J. Chem. Phys., 1999, 111, 7139; doi 10.1063/1.480006.

34. Bras R.E., Shull K.R., Macromolecules, 2009, 42, 8513; doi 10.1021/ma9013687

35. Leermakers F.A.M., Scheutjens J.M.H.M., J. Chem. Phys., 1988, 89, 3264; doi 10.1063/1.454931 


\title{
Вплив розподілу центрів зв'язування вздовж головного ланцюга на температурно залежні структурні властивості в асоціативних полімерних розчинах
}

\begin{abstract}
К.-Г. Ган, К.-Ф. Жанг, Й.-Г. Ма
Школа математики, фізики і біології, університет науки і технологій Внутрішньої Монголії, Баоту 014010, Китай

Вплив розподілу центрів зв'язування (stickers) вздовж головного ланцюга на структурні властивості в асоціативних полімерних розчинах вивчається з використанням ґраткової моделі самоузгодженого поля. Виявлено лише дві неоднорідні морфології, а саме мікрофлуктуаційну гомогенну (МФГ) та міцелярну морфології. Якщо система $є$ охолодженою, тоді зменшується вміст розчинника всередині агрегатів. Коли відстань між центрами зв'язування вздовж головного ланцюга збільшується, тоді зростають температурно залежний діапазон агрегації в морфології МФГ і півширина піку питомої теплоємності для переходу гомогенні розчини-МФГ, а симетрія піку - зменшується. Проте, з ростом відстані між центрами зв'язування вище згадані три величини, пов'язані з міцелами, поводять себе інакше. Показано, що різний характер спостережених переходів може пояснюватися структурними змінами, які супроводжують заміну розчинників в агрегатах на полімери, що узгоджується з результатами експерименту. Знайдено, що вплив відстані між центрами зв'язування на ці два переходи можна також трактувати на мові внутрішньоланцюгових і міжланцюгових асоціацій.
\end{abstract}

Ключові слова: структурні властивості, самоузгоджене поле, асоціативний полімер 